\title{
ARTÍCULOS
}

\section{LA LUCHA DE LOS ANTIGUOS TRABAJADORES FORZADOS ESPAÑOLES DEL III REICH POR SER RECONOCIDOS COMO VÍCTIMAS DEL NAZISMO (1956-1972)}

\author{
The Struggle of the Former Spanish Forced Workers of the Third Reich for recognition \\ as victims of Nazism (1956-1972)
}

\section{Antonio Muñoz Sánchez}

Investigador del Instituto de Ciências Sociais - Universidade de Lisboa Investigador Beatriu de Pinós- Universitat Rovira i Virgili de Tarragona urtier@hotmail.com

Orcid: 0000-0003-4904-2685

Recibido: 09-06-2020 - Aceptado: 11-10-2020

Cómo citar este artículo/Citation:

Antonio Muñoz Sánchez, "La lucha de los antiguos trabajadores forzados del III Reich por ser reconocidos como víctimas del nazismo (1956-1972)", Hispania Nova, 19 (2021): 325-352.

DOI: https://doi.org/10.20318/hn.2021.5884
Copyright: (c) HISPANIA NOVA es una revista debidamente registrada, con ISSN 1138-7319 y Depósito Legal M 9472-1998. Los textos publicados están -si no se indica lo contrario- bajo una licencia Reconocimiento-Sin obras derivadas 3.0 España de Creative Commons. Puede copiarlos, distribuirlos y comunicarlos públicamente siempre que cite su autor y la revista y la institución que los publica y no haga con ellos obras derivadas. La licencia completa se puede consultar en: http://creativecommons.org/licenses/by-nd/3.0/es/deed.es
Resumen: El artículo se ocupa de un capítulo poco conocido del exilio de la Guerra Civil: el combate que miles de españoles forzados a trabajar para los alemanes durante la Segunda Guerra Mundial libraron años más tarde para lograr una indemnización de la RFA como víctimas del nazismo. Comienza trazando las líneas maestras de la historia de los trabajadores forzados españoles en la Europa de Hitler. Prosigue con una somera descripción de la política de indemnización a las víctimas del III Reich impulsada por el gobierno de Konrad Adenauer. Por último disecciona, en base a documentación primaria, el largo y complejo proceso administrativo y judicial que acabó llevando a aquellos republicanos españoles a ser reconocidos, del mismo modo que sus compañeros deportados a Mauthausen, como perseguidos por el nazismo y obtener así una indemnización alemana.
Palabras clave: Segunda Guerra Mundial, exilio republicano, trabajo forzado, justicia, memoria.

\begin{abstract}
The text deals with a little known chapter of the Spanish Civil War exile: the struggle that thousands of Spaniards forced to work for the Germans during World War II put forward years later to obtain compensation from the FRG as victims of Nazism. It begins by tracing the main lines of the history of Spanish forced laborers in Hitler's Europe. It continues with a brief description of the policy of compensation for the victims of the Third Reich promoted by Konrad Adenauer's government. Finally, it dissects, on the basis of archival sources, the long and complex administrative and judicial process that ended up leading those Spanish Republicans to be recognized, in the same way as their comrades deported to Mauthausen, as persecuted of Nazism and to obtain German compensation for it.
\end{abstract}


Keywords: World War II, Spanish Republican

Exile, Forced Labor, Justice, Memory.

A finales de julio de 1965, la televisión alemana emitió en horario de máxima audiencia «Refugiados de la Guerra Civil española», una pieza del magazine mensual de actualidad política Panorama, producido por la Norddeutscher Rundfunk (NDR) y dirigido por el prestigioso publicista e historiador Joachim Fest ${ }^{1}$. El reportaje abordaba una cuestión del todo desconocida para el alemán medio en aquellos años: las enormes trabas que miles de españoles represaliados por los nazis durante la Segunda Guerra Mundial estaban encontrando a la hora de acceder a las indemnizaciones establecidas por la República Federal de Alemania (RFA) para las víctimas del III Reich. Grabado casi íntegramente en Toulouse, «Refugiados de la Guerra Civil española» mostraba a decenas de veteranos republicanos residentes en la ciudad y daba voz a cuatro de ellos: Bernardo Lairón, José Artime, Alberto Rubio y Fernando Martín. Los cuatro buscaban obtener una indemnización alemana, aunque sus experiencias durante la Segunda Guerra Mundial habían sido muy diferentes. El valenciano Bernardo Lairón y el asturiano José Artime habían sido deportados desde Francia a campos de concentración en el Reich, mientras que el andaluz Alberto Rubio y el madrileño Fernando Martín habían sido forzados a trabajar en Francia para los ocupantes alemanes.

Cuando hoy día los españoles piensan en sus víctimas del nazismo, inmediatamente les vienen a la mente los casi diez mil republicanos deportados a los campos de concentración. Sobre su trágica historia se han publicado numerosos estudios académicos, ensayos, novelas y autobiografías, existen bases de datos con las biografías de cada uno de ellos, se han realizado películas y documentales, y desde hace décadas diversas organizaciones celebran en su memoria actos de homenaje, a los que solo en 2019 se sumó el gobierno español al establecer el 5 de mayo, fecha de la liberación de

\footnotetext{
${ }^{1}$ https://daserste.ndr.de/panorama/archiv/1965/panorama2205.html
} 
Mauthausen en 1945, como el día del recuerdo a las víctimas españolas del nazismo ${ }^{2}$. En abierto contraste con los deportados, los trabajadores forzados españoles del III Reich son casi una hoja en blanco para los historiadores, no existe conciencia de que fueran perseguidos por la Alemania nazi, nadie se ha preocupado de realizar una lista con sus nombres, no se encuentran apenas referencias a ellos en los archivos, centros de documentación o museos españoles y solo un puñado de descendientes les recuerdan con publicaciones y actos de homenaje en algunas localidades de la costa atlántica de Francia y en las Islas del $\mathrm{Canal}^{3}$. En vista de tal situación, sería lógico concluir que la problemática descrita por Panorama en aquella emisión de verano de 1965 se acabó saldando favorablemente para los deportados Bernardo y José, mientras que los trabajadores forzados Alberto y Fernando habrían visto rechazadas sus solicitudes de indemnización.

Las siguientes páginas dejarán en evidencia lo erróneo de esta asentada visión sobre las víctimas españolas del nazismo. Demostrarán que, del mismo modo que los recluidos en campos de concentración, los republicanos obligados a servir a la economía de guerra nazi fueron reconocidos por la RFA como perseguidos políticos del Reich y por tanto indemnizados. A manera de introducción, se trazarán las líneas maestras de la historia del trabajo forzado durante la Segunda Guerra Mundial y el papel de los exiliados españoles. A continuación, se expondrán los fundamentos de la política alemana de compensación a los represaliados por el nazismo. Tomando como hilo conductor los casos de Alberto Rubio y de Fernando Martín, la tercera parte se dedicará a la lucha librada durante los años sesenta por los antiguos trabajadores forzados españoles para lograr ser reconocidos por la RFA como represaliados políticos del régimen de Hitler.

\footnotetext{
${ }^{2}$ Sobre el estudio y la memoria de la deportación de españoles a los campos de concentración nazis, véase Sara J. Brenneis, Spaniards in Mauthausen. Representations of a Nazi Concentration camp, 1940-2015 (Toronto: University of Toronto Press, 2018). La declaración del gobierno con motivo del primer día de homenaje a las víctimas españolas del nazismo, celebrado en 2020, se puede consultar en https://www.lamoncloa.gob.es/consejodeministros/Paginas/enlaces/050520-enlace-nazismo.aspx

${ }^{3}$ Scott Soo, "Ambiguities at Work: Spanish Republican Exiles and the Organisation Todt in Occupied Bordeaux", Modern and Contemporary France, 15 (2007): 457-477; Martí Crespo, Republicanos en los campos nazis del Canal de la Mancha (Barcelona: UOC, 2015); Gabrielle García, Plaza de los Republicanos españoles. Testimonio de exiliados en Bretaña (Zaragoza: Comuniter, 2015); Carlos Ruiz García, Cartas a un amigo. 1939-1944: un republicano español de Barcelona a Burdeos (s.1.: Pleine Plage, 2011).
} 


\section{ROTSPANIER, TRABAJADORES FORZADOS EN LA EUROPA DE HITLER}

Durante la Segunda Guerra Mundial, la Alemania nazi recurrió de forma masiva al uso de mano de obra extranjera para sostener su economía ${ }^{4}$. Solo en el territorio del Reich, trece millones de europeos fueron empleados en todos los sectores productivos, con especial incidencia en la industria armamentística. Más del $80 \%$ eran trabajadores forzados, procedentes en su gran mayoría de los países ocupados del este de Europa, y el resto eran voluntarios, reclutados en países satélites o amigos con los que Alemania estableció convenios de emigración, entre ellos la España de Franco ${ }^{5}$. Al final de la guerra, los extranjeros ocupaban uno de cada cuatro empleos en Alemania: seis millones eran trabajadores civiles, 2,2 millones prisioneros de guerra y 700.000 internos en campos de concentración. Por otro lado, también en los países ocupados los alemanes obligaron a más de diez millones de personas a malvenderles su mano de obra ${ }^{6}$.

En los Juicios de Núremberg, el sistema de semiesclavitud impuesto por los alemanes a millones de europeos fue considerado como crimen de guerra y crimen contra la humanidad, y el máximo responsable del reclutamiento forzoso, Fritz Sauckel, recibió sentencia de muerte ${ }^{7}$. Sin embargo, frente al mal absoluto que significó la aniquilación de millones de personas en los campos de concentración y la brutalidad sin límites del propio conflicto bélico, el fenómeno del trabajo forzado fue visto durante décadas como un aspecto marginal de la Segunda Guerra Mundial y apenas fue

\footnotetext{
${ }^{4}$ Ulrich Herbert, Fremdarbeiter. Politik und Praxis des „Ausländer-Einsatzes“ in der Kriegswirtschaft des Dritten Reiches (Bonn: Dietz, 1999).

${ }^{5}$ La historia de los 10.000 emigrantes españoles voluntarios a la Alemania nazi está bien estudiada. Véanse, Rafael García Pérez, "El envío de trabajadores españoles a Alemania durante la segunda guerra mundial", Hispania, XLVIII/170, (1988): 1031-1065; José Luis Rodríguez Jiménez, Los esclavos españoles de Hitler. La historia de los miles de españoles enviados a trabajar a la Alemania nazi (Barcelona: Planeta, 2002); Harmut Heine, "El envío de trabajadores españoles a la Alemania nazi, 19411945”, Migraciones y Exilios, 7 (2006): 9-26; Maurició Janué i Miret, “'Woe Betide Us If They Win!': National Socialist Treatment of the Spanish 'Volunteer' Workers", Contemporary European History, 23/3 (2014): 329-357.

6 Michael T. Allen, Hitler's Slave Lords: The Business of Forced Labour in Occupied Europe (Gloucestershire: Tempus, 2004).

7 Steffen Raßlof, Fritz Sauckel. Hitlers „Muster-Gauleiter“und Sklavenhalter“ (Erfurt: Landeszentrale für politische Bildung Thüringen, 2008).
} 
estudiado $^{8}$. Sólo a partir de los años noventa, en buena parte como reacción a las reclamaciones masivas de indemnización por parte de antiguos trabajadores de Europa del este, la historiografía y el conjunto de la opinión pública alemana comenzaron a valorar su importancia, dando paso a una cascada de publicaciones, congresos, exposiciones y centros de documentación que no dejan de crecer desde entonces ${ }^{9}$. En el conjunto de Europa, la investigación y el conocimiento público del tema son, sin embargo, relativamente escasos. Durante la guerra, trabajar para los alemanes se consideró en muchos países una forma de colaboración con el enemigo y por ello fue estigmatizado y borrado de la memoria colectiva tras 1945. De la mano de una joven generación de historiadores, la situación está cambiando en los últimos años, no ya solo en el ámbito de la producción historiográfica sino también en el de la difusión pública ${ }^{10}$.

Los estudios sobre el trabajo forzado durante la Segunda Guerra Mundial nos presentan una realidad compleja y en constante transformación. El empleo de extranjeros en el Reich no se realizó siguiendo un plan sino como respuesta improvisada a una necesidad de mano de obra cada vez más perentoria, a medida que se alargaba la guerra y las levas de jóvenes alemanes dejaban desocupados millones de puestos de trabajo. El reclutamiento fue muy dispar según los países, aunque la tendencia global fue a una evolución desde la voluntariedad hasta la recluta forzada e incluso la deportación en los últimos dos años de la guerra. El trato a los obreros extranjeros en el Reich y en los países ocupados variaba según criterios raciales y políticos. Destinados al exterminio, los judíos trabajaban hasta la extenuación. Los polacos y soviéticos eran explotados sin miramientos además de sufrir discriminación racial, al punto de ser condenados a muerte si mantenían relaciones íntimas con alemanas. Por su parte, los trabajadores de países de Europa occidental, que Berlín esperaba fuesen sus aliados tras la guerra, recibían un trato comparativamente decente; holandeses, belgas o franceses

\footnotetext{
8 Excepción relevante es el libro de Edward L. Homze, Foreign Labor in Nazi Germany (Princeton: Princeton University Press, 1967).

9 Henning Borggräfe, Zwangsarbeiterentschädigung: Vom Streit um 'vergessene Opfer' zur Selbstaussöhnung der Deutschen (Göttingen: Wallstein, 2014). El museo de referencia en Alemania sobre el trabajo forzado está en Berlín: www.ns-zwangsarbeit.de

10 En el ámbito historiográfico destaca Patrice Arnaud, Les STO. Histoire des français requis en Allemagne nazie, 1942-1945 (París: CNRS, 2010); en el de la difusión "Grossraum - Organisation Todt and Forced Labour in Norway 1940-45", exposición de 2017 que por vez primera tematizó en Noruega el trabajo forzado durante la ocupación nazi: https://www.tingenesmetode.no/about-the-conference
} 
tenían las mismas condiciones de trabajo y sueldo que los alemanes ${ }^{11}$. Una de las principales excepciones a esta norma fueron los enemigos políticos del III Reich, antifascistas de toda condición entre los que destacaban por número y reputación los exiliados republicanos españoles ${ }^{12}$. Aquellos mismos que habían combatido a la Legión Cóndor y a los que la propaganda nazi presentaba como peligrosos comunistas, «Sowjetspanier»o «Rotspanier» ${ }^{13}$.

Cuando el ejército alemán lanzó su ofensiva sobre Francia en mayo de 1940 se encontraban en el país 140.000 refugiados españoles de la Guerra Civil, de los cuales, grosso modo, 100.000 eran antiguos combatientes, y 40.000 mujeres, ancianos y niños ${ }^{14}$. La mitad de los hombres adultos se habían enrolado en las Compañías de Trabajadores Extranjeros (CTE), y la mayoría estaban destacados en la frontera norte reforzando la Línea Maginot. Un número indeterminado murió enfrentándose a los alemanes, decenas de miles huyeron hacia el sur y más de 7.000 fueron capturados y enviados campos de prisioneros de guerra (stalags) en el Reich junto a 1,8 millones de soldados franceses. En los meses siguientes, ante la negativa del gobierno franquista a hacerse cargo de ellos, Berlín ordenó el envío de los españoles a Mauthausen ${ }^{15}$. Tras el armisticio del 22 de junio de 1940, Francia fue dividida en una zona ocupada y una zona libre, donde se instaló la dictadura del mariscal Phillipe Pétain. El conocido como régimen de Vichy impulsó una política anticomunista, antisemita y xenófoba, que afectó directamente a los refugiados republicanos españoles. Miles de ellos fueron recluidos en los campos de internamiento de Argelès, Rivesaltes, Le Vernet, Septfonds, Noé y otros $^{16}$. Y unos 70.000 tuvieron que servir en los Grupos de Trabajadores Extranjeros (GTE) tanto en Francia como en Argelia, construyendo infraestructuras o dedicándose a labores del campo. Pese a no tener libertad de movimiento y no cobrar salario, los

\footnotetext{
${ }^{11}$ Mark Spoerer, Zwangsarbeit unter dem Hakenkreuz. Ausländische Zivilarbeiter, Kriegsgefangene und Häftlinge im Deutschen Reich und im besetzten Europa 1939-1945 (Stuttgart/Munich: DVA, 2001).

${ }^{12}$ Fabian Lemmes, Arbeiten für das Reich. Die Organisation Todt in Frankreich und Italien (Firenze: Ph. D. European University Institute, 2009), capítulo 3.

${ }^{13}$ Stefanie Schüler-Springorum, Krieg und Fliegen. Die Legion Condor im Spanischen Bürgerkrieg (Padeborn: Ferdinand Schöningh, 2010).

${ }^{14}$ Geneviève Dreyfus-Armand, El exilio de los republicanos españoles en Francia (Barcelona: Crítica, 2000).

${ }^{15}$ David W. Pike, Spaniards in the Holocaust: Mauthausen, the Horror on the Danube (London: Routledge, 2000).

${ }^{16}$ Grégory Tuban, Camps d'Étrangers. Le contrôle des réfugiés venus d'Espagne (1939-1944) (Paris: Nouveau Monde, 2018).
} 
españoles de los GTE se sentían al menos protegidos frente a peligros reales como la repatriación a España o la deportación a Alemania ${ }^{17}$. Pero su suerte iba a cambiar bien pronto.

La invasión de la Unión Soviética movilizó a partir del verano de 1941 al grueso del ejército alemán y produjo un descenso de efectivos en los países ocupados de Europa occidental. Para evitar que los Aliados aprovechasen esta situación y lanzasen una ofensiva, Hitler ordenó construir una gigantesca línea defensiva a lo largo de los casi $3.000 \mathrm{kms}$. de costa entre Hendaya y el Cabo Norte. El, así llamado, Muro Atlántico debía convertir al continente en una fortaleza inexpugnable, según proclamaba la propaganda alemana ${ }^{18}$. De hacer realidad este proyecto faraónico se ocuparía la Organización Todt (OT), organismo de carácter paramilitar que seguía a la Wehrmacht por toda Europa reparando infraestructuras dañadas en los combates y creando otras para asegurar el control del territorio conquistado. Su modus operandi consistía en contratar empresas de construcción y poner a su disposición la logística, la financiación y la mano de obra. Sus enormes recursos, procedentes en parte del saqueo de los países ocupados, y su eficaz burocracia descentralizada, otorgaban a la OT una gran capacidad operativa. Por todo el continente puso en pie o mejoró carreteras, puentes, fortificaciones, puertos, bases submarinas, canales, vías férreas, aeródromos, lanzaderas para cohetes, etc., completando, en palabras de la inteligencia militar británica, «el programa constructivo más impresionante desde la época de los romanos» ${ }^{19}$. Tras la muerte de su fundador Fritz Todt en febrero de 1942, la OT quedó en manos del ministro de armamento Albert Speer, quien la convirtió en un pilar de la economía de guerra nazi y en el mayor empleador de Europa ${ }^{20}$. Hasta un millón y medio de voluntarios, forzados, prisioneros de guerra y deportados a campos de concentración llegó a tener el multinacional ejército de trabajadores de la OT.

\footnotetext{
${ }^{17}$ Peter Gaida, "Les étrangers en surnombre". Les Groupements de travailleurs étrangers (GTE) sous le régimen de Vichy (s.1.: Lulu, 2016); Paul Estrade (dir.), El trabajo forzado de los españoles en la Francia de Vichy. Los GTE en Corrèze (1940-1944) (Madrid: UNED, 2017).

${ }^{18}$ H. W. Kaufmann, et al., The Atlantic Wall: History and Guide (Barnsley: Pen \& Sword, 2012).

${ }^{19}$ Supreme Headquarters Allied Expeditionary Force, Counter-Intelligence Sub-Division, Handbook of the Organisation Todt (London: MIRS, 1945).

${ }^{20}$ Adam Tooze, Ökonomie der Zerstörung. Die Geschichte der Wirtschaft im Nationalsozialismus (Bonn: bpb, 2007), 634 y ss.
} 
En Francia y en las Islas del Canal, 300.000 hombres participaron en la construcción del Muro Atlántico. Eran en su mayoría voluntarios franceses, alemanes, belgas y holandeses, atraídos por los altos salarios que se ofrecían. Algunos miles de exiliados españoles en la Francia libre también se enrolaron en la OT, hastiados de trabajar casi gratis en un GTE o como forma de salir de un campo de internamiento de Vichy ${ }^{21}$. En todo caso, la inmensa mayoría hizo oídos sordos a la poderosa maquinaria de propaganda de la OT y se negó a servir a los nazis. La situación cambiaría sin embargo a partir de 1942, cuando la necesidad de mano de obra para el Muro Atlántico se disparó y los alemanes exigieron a Vichy el envío de trabajadores. Unos 30.000 Rotspanier de los GTE, así como miles de recluidos en campos de internamiento o que vivían en ciudades del Midi esquivando a la policía, fueron enviados contra su voluntad a la costa atlántica, principalmente a Brest, Lorient, Saint Nazaire, La Rochelle y Burdeos, donde la OT estaba construyendo bases submarinas. Los rojos españoles fueron el mayor grupo de trabajadores forzados empleados por la OT en Francia y en las Islas del Canal, por delante de judíos y soviéticos 22 .

Todavía es muy poco lo que conocemos de los Rotspanier del Muro Atlántico. La historiografía alemana sobre el trabajo forzado apenas se ha ocupado de la OT, influida quizás por la imagen que de ella se ha tenido tradicionalmente como una organización técnica y apolítica dentro del régimen nazi ${ }^{23}$. A su vez, la historiografía francesa gira de forma obsesiva alrededor de los 600.000 compatriotas enviados al Reich en el contexto del Service du Travail Obligatoire (STO) impuesto a Vichy por los ocupantes alemanes en 1943. Aquellos que se querían librar de la emigración a Alemania podían trabajar en el Muro Atlántico, donde tenían libertad de movimiento y buenos salarios. Se entiende así que en Francia, la OT esté fuertemente connotada con la colaboración y haya interesado relativamente poco $^{24}$. En cuanto a la historiografía

\footnotetext{
21 Uno de ellos era el anarquista almeriense Pedro García León, cuya historia cuenta la película documental del año 2014 Cartas a María, realizada por su nieta Marta García Ribot.

${ }^{22}$ Peter Gaida, L'Organisation Todt en France (s.1.: Lulu, 2016).

${ }^{23}$ Franz Seidler, Die Organisation Todt. Bauen für Staat und Wehrmacht (Koblenz: Bernard\&Graefe, 1987).

24 Jean-Guy Dubernat, L'Organisation Todt. Une organisation allemande au coeur de la collaboration (Rennes: Ouest-France, 2014).
} 
británica, solo algunos estudios recientes rompen la espesa niebla que desde hace décadas cubre a los trabajadores forzados en las Islas del Canal ${ }^{25}$.

En definitiva, la historia de los trabajadores forzados españoles que construyeron el Muro Atlántico durante la Segunda Guerra Mundial está por escribir. Como veremos a continuación, la lucha que años más tarde llevaron adelante miles de ellos para lograr una indemnización alemana puede ayudar no poco a acometer esa empresa pendiente.

\section{LAS INDEMNIZACIONES DE LA RFA A LAS VÍCTIMAS DEL NAZISMO}

Tras el proceso de Núremberg contra los máximos jerarcas del régimen nacionalsocialista, el interés por hacer pagar sus culpas a los responsables de la explotación de millones de trabajadores extranjeros durante la guerra se diluyó rápidamente. En los juicios celebrados por la administración militar americana a partir de 1946 en aquel mismo tribunal contra los consorcios industriales IG Farben, Krupp y Flick, las defensas sostuvieron que el uso de trabajadores forzados había sido impuesto por las autoridades y no ordenado ni deseado por las empresas. El más que dudoso argumento no solo convenció a los jueces, que impusieron penas muy leves, sino también al conjunto de la sociedad alemana, que en su deseo de sacudirse la culpa colectiva había decidido que Hitler y sus secuaces eran los únicos responsables de los excesos cometidos durante el III Reich. La impunidad fue alimentada además por las potencias occidentales que, preocupadas por el avance del comunismo en Europa central, impulsaron la partición de Alemania y la consiguiente creación de la RFA, rehabilitaron a los capitanes de la industria y al funcionariado nazi y renunciaron con el Acuerdo de Londres de 1953 a las reparaciones de guerra para no dañar a la aún frágil economía alemana. Todas estas circunstancias coadyuvaron para que, en muy pocos años, el trabajo forzado durante la Segunda Guerra Mundial desapareciera del debate público, los tribunales y la agenda política de la flamante Alemania Occidental ${ }^{26}$.

\footnotetext{
25 David W. Pike, “Les îles anglo-normandes sous l'occupation allemande et la singularité des Républicains espagnols en captivité", en Guerres mondiales et conflits contemporains, 4 (2015): 59-78, y 1 (2016): 119-138. Sobre el desinterés de los isleños por los trabajadores forzados, véase Gilly Carr, Caroline Sturdy Colls, "Taboo and Sensitive Heritage: Labour camps, burials and the role of activism in the Channel Islands, 1940-1945”, International Journal of Heritage Studies, 22-9 (2016): 702-715.

${ }^{26}$ Henning Borggräfe, Zwangsarbeiterentschädigung, 51 y ss.
} 
En ese contexto, el gobierno de Konrad Adenauer aprobó en junio de 1956 la Ley Federal de indemnización (Bundesentschädigungsgesetzt - BEG), piedra angular de la política alemana de compensación a las víctimas del nazismo durante décadas. Derecho a una indemnización tendrían, según la BEG, aquellas personas que hubieran sido perseguidas por el III Reich «a causa de su oposición política al nacionalsocialismo o a causa de su raza, creencia o Weltsanschauung» y presentasen solicitud antes del 31 de marzo de 1958. Las condiciones que debían cumplir los candidatos eran tan estrictas que en la práctica dejaban fuera a la mayoría de víctimas. Por un lado, no se considerarían las solicitudes de ciudadanos de países que mantuvieran relaciones diplomáticas con la RDA, a la que la RFA no reconocía como estado e intentaba aislar internacionalmente. De esta forma se excluía a la gran masa de represaliados por el nazismo, que procedían del bloque comunista. Tampoco se atenderían solicitudes de nacionales de países que hubieran firmado el Acuerdo de Londres por el que renunciaban a las reparaciones alemanas. La principal excepción al estricto principio de territorialidad de los solicitantes serían los refugiados y apátridas a fecha 1 de octubre de $1953^{27}$. Esta excepción, pensada para judíos del Este emigrados a Occidente tras la guerra, sería a la postre crucial para los Rotspanier.

Las indemnizaciones no estaban pues concebidas para los extranjeros sino básicamente para alemanes y personas de origen alemán exiliadas durante el III Reich. Pero también aquí se aplicaban importantes restricciones. Gitanos, homosexuales o delincuentes comunes no tendrían derecho a indemnización, al entenderse que la represión ejercida sobre ellos por las autoridades alemanas entre 1933 y 1945 no era específicamente nazi sino común a muchas naciones en aquella época. Otro tanto ocurría con los trabajadores forzados, que no habrían sido perseguidos por el régimen sino apenas reclutados para contribuir al esfuerzo de guerra. Los beneficiarios potenciales representaban, en fin, una parte ínfima de las víctimas, como expuso gráficamente un diputado socialdemócrata en el debate del proyecto de ley: de los 42.000 presos en Buchenwald en el momento de la liberación, sólo 1.800 tenían nacionalidad alemana, de los que más de la mitad eran homosexuales, delincuentes

\footnotetext{
${ }^{27}$ Hans Günter Hockerts, "Wiedergutmachung in Deutschland. Eine historische Bilanz 1945-2000", Vierteljahrshefte für Zeitgeschichte, 49 (2001), Heft 2: 167-214.
} 
comunes, etc., y solo 700 presos políticos, los únicos que entrarían en la categoría de víctimas del nazismo según la $\mathrm{BEG}^{28}$.

El carácter fuertemente restrictivo de la política de indemnizaciones de la RFA acabó por despertar críticas tanto dentro como fuera del país, y obligando al canciller Adenauer a abrir la mano. La principal concesión se haría a algunos gobiernos europeos que, presionados por asociaciones de antiguos deportados, reclamaron a Bonn que tomara ejemplo de su acuerdo con Israel por el que concedió 3.000 millones de marcos para compensar a supervivientes del Holocausto. Se llegó, así, a partir de 1959 a la firma de once acuerdos bilaterales de la RFA con países de Europa occidental que proveían 876 millones de marcos para las víctimas del nazismo, de cuya gestión se ocuparían los respectivos gobiernos. Esta suma fue destinada fundamentalmente al pago de pensiones para deportados y resistentes. Por otra parte, el gobierno de la RFA aprobaría en 1965 una revisión de la BEG que ampliaba las categorías de víctimas reconocidas y abría un nuevo plazo de solicitudes. En total, las indemnizaciones en el marco de la BEG alcanzarían los 65 millones de $\operatorname{marcos}^{29}$.

La gestión de las indemnizaciones quedó en manos de los estados federales, lo que hasta hoy dificulta la visión de conjunto $^{30}$. Cada Land contaba con su propio Servicio de Indemnizaciones, el cual a su vez disponía de varias oficinas repartidas por el territorio. Además de tramitar las solicitudes de los demandantes de la región, cada Land se especializó en algún grupo específico. Así por ejemplo, Renania Palatinado se encargó de la mayoría de casos de alemanes residentes en el extranjero, mientras que Renania del Norte-Westfalia hizo lo propio con los apátridas y refugiados. Cuando el Servicio de Indemnizaciones resolvía negativamente, se podía acudir a la vía judicial. Así lo hicieron decenas de miles de demandantes, apoyados en la red de abogados especializados en indemnizaciones alemanas que se fue creando por toda Europa ${ }^{31}$. Casi dos millones de personas reclamaron una indemnización. A la mitad les sería concedida,

\footnotetext{
${ }^{28}$ Ibídem.

${ }^{29}$ Hans Günter Hockers, Claudia Moisel, Tobias Winstel (eds.), Grenzen der Wiedergutmachung. Die Entschädigung fur NS-Verfolgte in West- und Osteuropa 1945-2000 (Göttingen: Wallstein, 2006).

${ }^{30}$ Otto Gnirs, "Die Entschädigungsbehörden”, en Bundesminister der Finanzen (ed.), Wiedergutmachung nationalsozialistischen Unrechts durch die Bundesrepublik Deutschland, Band VI (München: Beck, 1987).

31 Hans Günter Hockers, “Anwälte der Verfolgten. Die United Restitution Organisation”, en Ludolf Herbst, Constantin Goschler (eds.), Wiedergutmachung in der Bundesrepublik Deutschland (München: Oldenbourg, 1989).
} 
bien por resolución administrativa, bien por sentencia judicial. El enorme volumen de solicitudes, la escasez de personal, los exagerados requisitos probatorios reclamados a los solicitantes y el celo de muchos funcionarios en encontrar motivos para negar la indemnización, contribuyeron a complicar y dilatar, a veces más de una década, un proceso que muchas víctimas vivieron como una auténtica humillación. 650.000 solicitantes recibieron una compensación económica en un solo pago y otros 360.000 accedieron a una pensión vitalicia. Las cuantías de las prestaciones eran muy dispares. En el caso de privación de libertad se compensaba con apenas cinco marcos por día, mientras que las pensiones vitalicias por viudedad o invalidez superior al $25 \%$ eran bastante generosas ${ }^{32}$.

A finales de los años setenta, el grueso de las solicitudes presentadas al amparo de la BEG habían sido resueltas y para el gobierno alemán las indemnizaciones a las víctimas del nazismo era ya un asunto felizmente cerrado. Durante más de dos décadas, la gestión de las indemnizaciones se había desarrollado discretamente en el ámbito administrativo y judicial y apenas había encontrado eco en una opinión pública inmersa todavía en el silencio sobre las desgracias de la pasada guerra. Cuando, en la década de los noventa, los historiadores y el gran público descubrieron a los trabajadores forzados del III Reich, y el gobierno y las grandes empresas, por temor a ver dañada su imagen, crearon fondos multimillonarios para compensar a estas víctimas olvidadas del regimen hitleriano, ya nadie recordaba que, muchos años antes, un amplio grupo de antifascistas españoles obligados a construir el Muro Atlantico habían logrado, tras un largo pulso, ser reconocidos por la RFA como perseguidos políticos del nazismo ${ }^{33}$.

\section{LAS INDEMNIZACIONES ALEMANAS A LOS ROTSPANIER}

La aprobación de la BEG en 1956 suscitó escaso interés fuera de Alemania al no ser de aplicación, salvo casos excepcionales, a los nacionales de otros países. Para miles

\footnotetext{
${ }^{32}$ Christian Pross, Der Kleinkrieg gegen die Opfer (Frankfurt am Main: Philo, 1988).

${ }^{33}$ Sirva de ejemplo la siguiente cita, extraida del catálogo de la mayor exposición sobre trabajo forzado en el III Reich, que gira por Alemania desde 2010: "Los tribunales alemanes rechazaron hasta finales de los años ochenta casi todas las reclamaciones de indemnización de los antiguos trabajadores forzados. Solo en cinco casos se llegó a un acuerdo extrajudicial." Zwangsarbeit. Die Deutschen, die Zwangsarbeiter und der Krieg (Weimar: Stiftung Gedenkstätten Buchenwald und Mittelbau-Dora, 2010), 160.
} 
de españoles perseguidos por el nazismo y para los familiares de los asesinados, las indemnizaciones alemanas hubieran probablemente pasado totalmente desapercibidas de no haber sido por el empeño de algunas organizaciones de exiliados en difundirlas. Especialmente activa se mostró la Federación Española de Deportados e Internados Políticos (FEDIP), fundada en Toulouse en 1945 y cuyo secretario general durante décadas fue el anarquista catalán José Ester Borras ${ }^{34}$. Además de informar a través de su revista Hispania, la FEDIP escribió a centenares de familiares en España de fallecidos en campos de concentración, dándoles a conocer las indemnizaciones y explicando las gestiones necesarias para solicitarlas ${ }^{35}$.

Entre 1956 y 1958 se presentaron unas 2.000 solicitudes de españoles ante los Servicios de Indemnización alemanes ${ }^{36}$. Los demandantes eran en su inmensa mayoría deportados a campos de concentración que residían como apátridas en Francia o bien familiares de fallecidos en los campos que residían en España. Solo un pequeño número de demandantes eran antiguos trabajadores forzados. Entre ellos no estaban Fernando Martín y Alberto Rubio. Según declaró este último en 1965 a las cámaras de Panorama, no había presentado entonces solicitud porque su organización de exiliados le había informado de que las indemnizaciones estaban pensadas solo para los deportados a Alemania. Al igual que muchos antiguos compañeros de la OT, Fernando y Alberto presentarían su solicitud después de 1961 acogiéndose a la posibilidad que daba la ley alemana de hacerlo fuera de plazo si el demandante podía probar que no había sido informado correctamente sobre la BEG o no había oído hablar de ella en absoluto, y animados por abogados que les dieron esperanzas de éxito en vista del recorrido que estaban teniendo algunas peticiones presentadas por otros trabajadores forzados españoles.

Manuel Padilla fue uno de los pioneros que abrieron brecha a las reclamaciones de antiguos trabajadores forzados españoles, presentando su solicitud ante el Servicio de

\footnotetext{
${ }^{34}$ Violette Marcos, Juanito Marcos, José Ester Borras... Une vie de combats (1913-1980) (Les cahiers du Coquelicot, $\mathrm{n}^{\circ}$ 9).

${ }^{35}$ Circulares de la FEDIP para los familiares en España, octubre y noviembre de 1957, International Institute of Social History (IISH), Fondo José Ester, carpeta 41.

${ }^{36}$ La cifra es aproximada. Ante el Servicio de Indemnizaciones de Renania del Norte-Westfalia se presentaron 1.485, y calculamos que algunos cientos más lo serían en otros Länder. Servicio de Indemnizaciones de Renania del Norte Westfalia al Ministro de Interior del Land, 30.10.1959, Landesarchiv Nordrhein-Westfalen (LAV NRW), R 2614, Nr. 68.
} 
Indemnizaciones de Colonia en $1957^{37}$. Su historia era similar a las de decenas de miles de compañeros españoles obligados a construir el Muro Atlántico. Soldado del Ejército Popular de la República, cruzó los Pirineos camino del exilio a comienzos de 1939, trabajó en una CTE como metalúrgico, y tras el armisticio en un GTE reparando carreteras. El 2 de mayo de 1942, fue detenido en Roanne y obligado a construir bunkers en Guersney, Saint Malo y la pequeña isla de Cézembre hasta la liberación en agosto de 1944. Ante el desconocimiento general sobre las condiciones de vida de los trabajadores españoles del Muro Atlántico, el Servicio de Indemnizaciones de Colonia solicitó información a las administraciones alemana, francesa y británica sobre diversos campos de la OT en los que habían estado Manuel Padilla y otros solicitantes. Las respuestas recibidas no eran coincidentes, pero en su mayoría presentaban las condiciones de los españoles como relativamente buenas ${ }^{38}$. Con las escasas evidencias recopiladas, el Servicio de Indemnizaciones resolvió que los Rotspanier de la OT no debían ser considerados como perseguidos políticos del nazismo. Nada indicaba que hubieran sido tratados de manera diferente a las decenas de miles de franceses que, por las propias exigencias de la guerra y no por una animosidad de tipo ideológico, fueron reclutados para construir el Muro Atlántico. El Servicio de Indemnizaciones reconoció en todo caso algunas situaciones excepcionales como las de los campos de trabajo de las Islas del Canal, cuyas condiciones extremas pudieron ser finalmente documentadas ${ }^{39}$. Sin embargo, al poco tiempo el Servicio de Indemnizaciones se echó atrás y paralizó todos los casos de Rotspanier del Muro Atlántico hasta que no se aclarase la vía judicial a la que algunos habían decidido acudir ${ }^{40}$.

Efectivamente, Manuel Padilla y muchos otros compañeros españoles no aceptaron la resolución del Servicio de Indemnizaciones y la recurrieron ante la Justicia. El hecho de que algunas solicitudes hubieran sido resueltas positivamente y la propia aceptación por parte de los Tribunales de los casos de revisión, animaron a su vez a varios miles de españoles de la OT a presentar sus solicitudes ante el Servicio de

\footnotetext{
${ }^{37}$ Expediente de Miguel Padilla, Servicio de Indemnizaciones de Renania del Norte-Westfalia.

${ }^{38}$ Embajada de la RFA en París al Servicio de Indemnizaciones, 30.3.1960, LAV NRW, R 2614, Nr. 277; consulado de la RFA en Burdeos al Servicio de indemnizaciones, 29.6.1960, LAV NRW, R 2614, Nr. 29.

39 Servicio de Indemnizaciones de Renania del Norte Westfalia al Ministro del Interior del Land, 16.4.1962, LVA, NRW R 2614, Nr. 272.

${ }^{40}$ Nota interna del Servicio de Indemnizaciones de Renania del Norte Westfalia sobre los Rotspanier, 20.5.1968, LVA, NRW R 2614, Nr. 273.
} 
Indemnizaciones. Fernando Martín y Alberto Rubio fueron dos de ellos. Fernando Martín formaba parte de un GTE cuando, en septiembre de 1942, fue llevado a La Pallice junto a otros compatriotas para construir la base submarina alemana de La Rochelle. En marzo de 1943 le enviaron a Camiers, un pueblo cercano a Boulogne-surMer, donde construyó bunkers. A finales de ese año, durante un nuevo traslado, esta vez a Alemania, consiguió escapar y vivió en la clandestinidad hasta la liberación. Por su parte, Alberto Rubio fue detenido por la Gestapo en Toulouse en otoño de 1943 y, tras pasar por los campos de internamiento de Noé y Dannes, acabó en Hazebrouck, cerca de Lille. Allí construyó lanzaderas para los cohetes V1. En marzo de 1944, aprovechando la confusión tras un bombardeo aliado, se escapó y vivió en la clandestinidad. El Servicio de Indemnizaciones resolvió negativamente las solicitudes de Fernando Martín y Alberto Rubio, y ambos acudieron entonces a la vía judicial ${ }^{41}$.

El Tribunal Regional (Landesgericht) de Colonia que recibió la mayoría de las demandas contra las resoluciones del Servicio de Indemnizaciones, hubo de profundizar en la cuestión de si los Rotspanier del Muro Atlántico habían sido víctimas de represalias por parte de las autoridades alemanas y si esas tenían motivación política. En una declaración jurada ante notario, Alberto Rubio afirmó que había sido detenido y sin más explicaciones enviado a trabajar a Hazebrouck, donde nunca supo quién era su empleador ${ }^{42}$. Declarando ante el juez, Fernando Martín sostuvo que el campo de la OT en La Pallice estaba rodeado por alambradas, tenía fuerte vigilancia militar, y no podía salir ni mantener correspondencia ${ }^{43}$. El trabajo era extenuante y peligroso, los turnos de diez o más horas, la comida escasa, y sin descanso asegurado los domingos. Tanto en el lager como en la obra eran víctimas ocasionales de malos tratos, humillaciones e insultos. En fin, Fernando y Alberto sostenían que habían sido llevados contra su voluntad a los campos de la OT, donde fueron privados de libertad, obligados a trabajar en condiciones extremas y sometidos a trato vejatorio. Y todo ello a causa de la hostilidad que les profesaban los alemanes por ser Rotspanier, rojos españoles. La

\footnotetext{
${ }^{41}$ Expedientes de Fernando Martín y Alberto Rubio, Servicio de Indemnizaciones de Renania del NorteWestfalia.

42 Declaración jurada de Alberto Rubio ante la Policía de Toulouse, 22.12.1964, Expediente Alberto Rubio, Servicio de Indemnizaciones de Renania del Norte-Westfalia.

43 Declaración de Fernando Martín ante el Landesgericht Köln, 10.5.1965. Expediente de Fernando Martín, Servicio de Indemnizaciones de Renania del Norte-Westfalia. A esta declaración se hace referencia en el reportaje de Panorama.
} 
versión presentada ante el Landesgericht por antiguos funcionarios de la OT fue muy diferente. Negaron los malos tratos a los exiliados españoles y afirmaron que la dureza de los campos de trabajo era consecuencia lógica del contexto bélico ${ }^{44}$. Las declaraciones dibujaron por lo demás una gran variedad de campos de trabajo repartidos por la costa francesa. En el norte las condiciones de vida eran ásperas, mientras que en el sur resultaban más llevaderas. Como ejemplo máximo de confort se citaba de forma recurrente la Caserna Niel de Burdeos, donde los 3.000 españoles allí alojados gozaban de cierta libertad de movimiento y tenían sus propias actividades culturales y de asueto. Responsable del campo era el hispano-alemán José María Otto Warncke, él mismo exiliado de la Guerra Civil, quien había logrado convencer a los responsables de la OT en Burdeos y al propio Albert Speer durante su visita a la ciudad en diciembre de 1942 de que los Rotspanier rendirían más en las obras de construcción de la base submarina alemana si recibían un trato correcto ${ }^{45}$.

El Landesgericht emitió el grueso de sus sentencias sobre los casos presentados por los Rotspanier del Muro Atlántico a partir de 1964. Siguiendo el criterio del profesor Wilhelm Alff del Instituto de Historia Contemporánea de Munich, al que se había pedido informes sobre los exiliados españoles, el Tribunal consideró probado que el régimen nazi los había considerado como potenciales enemigos politicos ${ }^{46}$. Sin embargo, ello no significaba que las autoridades militares alemanas en Francia hubieran visto en los Rotspanier un peligro real e inmediato. De haber sido así, en lugar de enviarlos a trabajar en obras de carácter estratégico en Francia, los hubiera deportado a campos de concentración en Alemania. Haber combatido a Franco, entendían sus señorías, no convertía automáticamente a los Rotspanier en enemigos de Hitler. Solo quien tuviera un conocimiento directo de la política alemana, estaba en situación de entender al régimen nazi y de desarrollar una actitud opositora consecuente que llevara

\footnotetext{
${ }^{44}$ Declaración ante el Landesgericht Köln del testigo Willi Braun, educador de guardias para los campos de la OT en Francia, durante el proceso de Agustín Fabra contra Renania del Norte Westfalia, 9.12.1963, Expediente Agustín Fabra, Servicio de Indemnizaciones de Renania del Norte-Westfalia.

45 Scott Soo, "Ambiguities at Work". Sobre la visita del ministro de Armamento del Reich a la caserna Niel, ver Albert Speer, Spandauer Tagebücher (Berlin: Propyläen, 1994), 251.

46 Wilhelm Alff, Gutachten zur Frage der republikanischen spanischen Flüchlinge ("Rotspanier"), 26.11.1964, LAV, R 2172, Nr. 24.
} 
al III Reich a reprimirla. Y este conocimiento directo, concluía el Tribunal su alambicada argumentación, no lo tenían los extranjeros salvo en raras excepciones ${ }^{47}$.

A la altura de 1965, los antiguos trabajadores españoles del Muro Atlántico que aspiraban a una indemnización de la RFA tenían buenas razones para el desánimo. Su combate contra un sistema administrativo y judicial alemán menos comprometido con los damnificados del nazismo que con las arcas del Estado, resultaba demasiado desigual. Aunque en menor grado, también los antiguos deportados españoles sufrían esta misma indefensión. Un estudio sobre la praxis de la BEG elaborado por la Federación Internacional Libre de Deportados e Internados Políticos (FDNIP) describía los casos más flagrantes y concluía que existía «hacia los refugiados españoles deportados y sus familias una actitud [...] claramente hostil: se tiene la sensación de que continuamente se busca con encono nuevas vías para negarles la satisfacción a sus peticiones» ${ }^{48}$. La situación resultaba todavía más dolorosa para los exiliados en vista de las atenciones que la RFA dispensaba a los veteranos de la División Azul. A comienzos de 1965, el Bundestag aprobó una ley que proveía 1,7 millones de marcos para el pago de pensiones a los casi 50.000 españoles voluntarios de la Wehrmacht. Se trataba, en palabras de un diputado de la mayoría de gobierno, de un «acto de humanidad» ${ }^{49}$.

Denunciar este agravio comparativo fue precisamente lo que impulsó a Panorama a realizar el documental «Refugiados de la guerra de España». El programa se ponía claramente de parte de los republicanos, a los que presentaba como víctimas de un gobierno alemán que no dudaba en sacrificar la ética en el altar de la realpolitik. Apostado ante el modesto local de una organización caritativa de Toulouse donde se entregaban alimentos a ancianos exiliados españoles sin recursos, el reportero Winfried Scharlau afirmaba contundente:

Estos españoles víctimas del nacionalsocialismo han tenido poca ayuda y comprensión de las autoridades alemanas, quizás porque indemnizarles no traería ningún beneficio político a la República Federal. Y es que Franco, y esto se puede decir con certeza, no va a interceder por sus enemigos ante [las autoridades de] Bonn. De lo contrario, sus indemnizaciones habrían sido tratadas de

\footnotetext{
${ }^{47}$ Sentencia del Landesgericht Köln en el caso Fernando Martín contra Renania del Norte Westfalia, 21.12.1965, Expediente Fernando Martín, Servicio de Indemnizaciones de Renania del Norte-Westfalia.

${ }^{48}$ FILDIR, Informe sobre la compensación a las víctimas del nacionalsocialismo, s.f. [1967], IISH, Fondo Ester, carpeta 65.

${ }^{49}$ Walter Lehmann, Die Bundesrepublik und Franco-Spanien in den 50er Jahren (München: Oldenbourg, 2006), 205.
} 
forma tan benévola y generosa como las de la División Azul, que por supuesto no combatió contra sino a favor de la Alemania nazi ${ }^{50}$.

También el profesor Wilhelm Alff aparecía en el documental, con una corta pero incisiva declaración grabada ante los restos de una barraca del campo de internamiento de Le Vernet, al pie de los Pirineos, desde donde miles de refugiados españoles habían partido para los campos de concentración alemanes y para los campos de trabajo de la OT en el Muro Atlántico:

A raíz de la ocupación alemana [de Francia, los exiliados españoles] cayeron en la maquinaria represiva del nacionalsocialismo. Se ha de recalcar que fueron perseguidos por motivos políticos; no porque eran españoles, sino porque eran republicanos españoles. Traían de su país natal una clara conciencia de lo que significaba en nacionalsocialismo, que habian forjado por la intervención de Hitler en la Guerra Civil. La motivación política de su persecución fue claramente expresada por un preso, quien grabó en la pared de su celda las siguientes palabras: «detenido por los nazis por haber combatido a Franco» ${ }^{51}$.

Aunque ya era costumbre que Panorama fustigara a los conservadores alemanes por su escasa distancia crítica hacia el pasado dictatorial, «Refugiados de la guerra de España» escoció en los círculos de poder. A pocas semanas de que entrase en vigor una reforma de la BEG que debía mostrar al mundo la enorme empatía de la RFA con las víctimas del III Reich, aquel programa seguido «por millones de telespectadores» también en países vecinos, arrojaba una negra sombra sobre la política de indemnizaciones y dañaba, en definitiva, el buen nombre de la democracia alemana $^{52}$. No todos compartían sin embargo esta opinión. Para los muy nutridos sectores ultraconservadores no era el honor de la patria lo que estaba en cuestión sino sus recursos, por lo que el Estado debía mantenerse firme frente a las «desvergonzadas pretensiones de estos Rotspanier» ${ }^{53}$.

Sobrellevando toda clase de obstáculos, reveses y desprecios, miles de veteranos de la Guerra Civil continuaron la lucha para ver reconocidos sus derechos por parte de la RFA. Entre 1965 y 1969 llegaron a los Servicios de Indemnizaciones más de

\footnotetext{
${ }^{50}$ https://daserste.ndr.de/panorama/archiv/1965/panorama2205.html

${ }^{51}$ Ibídem.

${ }^{52}$ Regierungspräsident Köln a Niesert, 1.9.1965, LAV, NRW R 2614, Nr. 274.

53 Paul Coelestin Ettighoffer (veterano periodista y escritor de cierto éxito) al Servicio de Indemnizaciones de Colonia, 4.11.1965, LAV, NRW R 2614, Nr. 274.
} 
5.000 nuevas solicitudes de exiliados republicanos o de sus familiares desde España, Francia y otros países ${ }^{54}$. Aquellas presentadas por los antiguos trabajadores del Muro Atlántico se sumaron a las miles que seguían congeladas a la espera de que la Justicia pronunciara la última palabra sobre si se les debía o no considerar perseguidos políticos del nazismo. Tras la retahíla de sentencias negativas del Landesgericht Köln, los abogados de los españoles habían acudido al Oberlandesgericht Köln (Tribunal Superior de Justicia de Colonia), cuya sección $11^{\circ}$ presidida por Franz Joseph Wilhelmy se iba a ocupar durante varios años en exclusiva de los Rotspanier de la OT. Ironías de la historia, el juez que acabaría dándole la razón a los antifascistas españoles había flirteado en los inicios de su carrera en los años treinta con los nazis y había sido depurado por los americanos tras el fin de la guerra, aunque acabaría siendo rehabilitado a los pocos años ${ }^{55}$. Un recorrido vital que, por lo demás, no era muy diferente al de la inmensa mayoría de los juristas alemanes que ayudaron a construir y mantener el III Reich $^{56}$.

En su deseo de llegar hasta el fondo de la cuestión, Franz Joseph Wilhelmy puso en marcha, en sus propias palabras, «una verdadera investigación histórica» sobre los trabajadores españoles del Muro Atlántico ${ }^{57}$. Recopiló documentación de distintas administraciones y organismos del III Reich, y llamó a centenares de testigos. Ante el Tribunal comparecieron desde la anónima oficinista de un mando policial alemán en la Burdeos ocupada hasta el máximo responsable de la OT Albert Speer, una vez cumplida la condena de veinte años impuesta en el Juicio de Núremberg ${ }^{58}$. También declararon, ayudados de intérpretes, los veteranos exiliados españoles, que contestaron a preguntas muy precisas sobre las circunstancias de su detención o recluta forzada, sobre el viaje a la costa francesa, la estancia en los campos de la OT, las condiciones de trabajo, los horarios, etc. Además de los propios afectados, declararon o enviaron declaraciones

\footnotetext{
${ }^{54}$ La cifra es apenas una proyección del autor. En mayo de 1968 solo en Colonia había 5.000 casos no resueltos exclusivamente de españoles de la OT. Nota interna del Servicio de Indemnizaciones de Renania del Norte Westfalia sobre los Rotspanier, 20.5.1968, LAV, NRW R 2614, Nr. 273.

55 Acta personal del juez Franz Joseph Wilhelmy, LAV, R1039-AIII/54

${ }^{56}$ Marc von Miquel, "Juristen: Richter in eigener Sache", en Norbert Frei (ed.), Karrieren im Zwielicht. Hitlers Eliten nach 1945 (Frankfurt am Main: Campus, 2001), 165-214.

57 “Ein Anwalt im Wettlauf mit dem Tod. Kein Geld für ehemalige Franco-Gegner?”, Kölnischer Rundschau, 19 de octubre de 1969.

${ }^{58}$ Declaración de Albert Speer en el caso Manuel Padilla contra Renania del Norte Westfalia, 10.2.1969, Expediente Manuel Padilla, Servicio de Indemnizaciones de Renania del Norte-Westfalia.
} 
juradas desde Francia decenas de españoles que habían estado en los mismos campos o habían trabajado en las mismas obras que los demandantes ${ }^{59}$.

Caso tras caso, el Oberlandesgericht Köln fue desentrañando la compleja realidad de los trabajadores españoles de la OT y poniendo patas arriba los argumentos del Servicio de Indemnizaciones y del Landesgericht Köln para negarles el carácter de perseguidos políticos del nazismo. El Tribunal dio por probado que los exiliados de la Guerra Civil en Francia habían sido peor tratados en la OT que el resto de trabajadores de Europa occidental, y que la motivación para ello había sido de carácter ideológico. El envío de Rotspanier al Muro Atlántico no se había producido porque no fuesen considerados enemigos políticos del Reich, sino pese a ello ${ }^{60}$. La documentación nazi rescatada de los archivos era cristalina al respecto. Así por ejemplo, el juez citaba en una sentencia una comunicación de Reinhard Heydrich referida al trato a los Rotspanier datada en abril del 1941, en la que el jefe de las SS afirmaba: «La peligrosidad de esta gentuza [...] antialemana infestada de comunistas no necesita de mayores explicaciones ${ }^{61}$. Había sido pues la necesidad extrema de mano de obra la que había forzado a la OT a recurrir a los indeseables antifascistas españoles enrolados en los GTE de la Francia libre. Solo la voluntad de represión explicaba, según el juez, por qué a los republicanos españoles se les había privado de libertad en los lager del Muro Atlántico mientras trabajadores de otras nacionalidades tenían libertad de movimiento. El hecho de que en algunos campos de la OT, y muy especialmente la referida Caserna Niel en Burdeos, los españoles disfrutasen de un régimen bastante laxo no anulaba lo anterior, tratándose apenas de excepciones que confirmaban la regla. Buena parte del argumentario desplegado por el juez Franz Joseph Wilhelmy en diferentes sentencias se concentraba en la del caso Manuel Padilla contra Renania del Norte-Westfalia dictada en junio de 1970:

Es cierto que, a diferencia de los judios, el gobierno alemán no tomó medidas colectivas contra los llamados Rotspanier. Sin embargo, los dirigentes alemanes sí consideraron a los refugiados republicanos españoles potenciales enemigos ideológicos del orden

\footnotetext{
${ }^{59}$ Véanse por ejemplo las declaraciones de varios españoles en el caso Manuel Padilla contra Renania del Norte Westfalia, Expediente Manuel Padilla, Servicio de Indemnizaciones de Renania del NorteWestfalia.

${ }^{60}$ Walter Lehmann, Die Bundesrepublik und Franco-Spanien, 215.

${ }^{61}$ Reinhard Heydrich al ministro de Trabajo Franz Seldte, 7.4.1941, reproducido en una sentencia del Oberlandesgericht Köln, extractada en Rechtsprechung zum Wiedergutmachungsrecht, 18 (1967): 360.
} 
político alemán nacionalsocialista. Esta valoración [...] una y otra vez respaldada por pruebas documentales, se mantuvo durante la masiva integración de los refugiados españoles en la Organización Todt. [...] Ciertamente los Rotspanier fueron tratados de manera muy diversa [...]. Mientras algunos tenían libertad de movimiento [...], otros tuvieron que trabajar en condiciones de vida tan inhumanas, que se impone la comparación con los campos de concentración. Estas diferencias han encontrado una plausible explicación [...] en la declaración del antiguo ministro Speer [...]. Como era habitual en la elite dirigente nacionalsocialista, se produjo a lo largo de los años una lucha de poder entre Speer y Himmler, que también se trasladó al trato hacia los Rotspanier. Mientras que Himmler los veía ante todo como oponentes ideológicos a destruir que no merecían mejor trato que los presos en los campos de concentración, para Speer la prioridad era preservar un contingente de trabajadores [...] que apreciaba como buenos obreros, de forma que abogó en sus encuentros con Hitler por que se les tratara mejor. [...] [Speer no pudo sin embargo imponer su criterio sobre el terreno sino en casos excepcionales, porque la mayoría de funcionarios de la OT eran nazis radicales que trabajaban en la dirección marcada por Himmler]. El hecho de que una serie de grandes lager en los que fueron internados los republicanos españoles fueran dirigidos según el modelo de los campos de concentración, dificilmente puede ser interpretada como resultado de acciones individuales de los responsables del lager ${ }^{62}$.

Las sucesivas sentencias del Oberlandesgericht dibujaron un cuadro del hasta entonces desconocido archipiélago de campos de trabajo de la OT en el Muro Atlántico. En más de una veintena, los magistrados pudieron constatar de manera fehaciente que los republicanos españoles habían sido sometidos a «condiciones similares al cautiverio» por motivaciones políticas y debían por lo tanto ser compensados económicamente según establecía la BEG. Entre los campos indemnizables se contaban La Pallice y Camiers, en los que estuvo Fernando Martín, y el de Dannes, por el que pasó Alberto Rubio ${ }^{63}$. Las fechas límite del periodo a indemnizar por la estancia en un lager de la OT se fijaron de manera general en el 22 de junio de 1941 (día en que Alemania atacó a la URSS y a partir de cuando recrudeció la persecución contra los comunistas en los países ocupados) y la propia liberación del campo en 1944 o 1945.

\footnotetext{
${ }^{62}$ Sentencia del Oberlandesgericht Köln en el caso Manuel Padilla contra Renania del Norte Westfalia, 12.6.1970, Expediente Manuel Padilla, Servicio de Indemnizaciones de Renania del Norte-Westfalia.

${ }^{63}$ Lista de campos indemnizables en Francia elaborada por el Servicio de Indemnizaciones de Colonia, 12.6.1972, LAV R 2614, Nr. 68. En la lista no se encuentra el campo de Hazebrouck, posiblemente por falta de evidencias documentales que dieran base a la declaración de Alberto Rubio.
} 
Sin embargo, el pulso entre la administración alemana y los antiguos trabajadores forzados españoles no iba a terminar aquí. Ante la perspectiva de tener que desembolsar millones de marcos del erario público a viejos y olvidados Rotspanier, el gobierno socialdemócrata de Renania del Norte Westfalia, de acuerdo con el gobierno federal, presentó recurso contra algunas sentencias del Oberlandesgericht Köln ante el Tribunal Federal de Justicia (Bundesgerichtshof) de Karlsruhe ${ }^{64}$. Para desolación de los impulsores de la iniciativa, cuanto menos llamativa tratándose de un gobierno de izquierdas, aquellas demandas acabaron siendo «rechazadas de forma lapidaria» por el alto tribunal ${ }^{65}$.

Aclarado definitivamente el frente judicial, a partir de junio de 1972 miles de solicitudes presentadas en la última década y que habían quedado paralizadas fueron rápidamente resueltas por los Servicios de Indemnizaciones. Como en el caso de los deportados a campos de concentración en Alemania, los refugiados españoles en Francia que a partir de 1941 hubieran estado en alguno de los campos indemnizables del Muro Atlántico recibieron 150 marcos por mes de reclusión y una pensión vitalicia si les había dejado secuelas físicas o psíquicas. Para aquellos excombatientes del Ejército Popular de la República, recibir del Servicio de Indemnizaciones el cheque con un pago único de varios miles de marcos o el ingreso mensual en su cuenta corriente representó seguramente un pequeño alivio para sus economías. Haber infligido una derrota limpia al estado sucesor del III Reich tampoco debió de ser para ellos una satisfacción menor.

\section{CONCLUSIONES}

En los años setenta del siglo pasado, unos 5.000 exiliados españoles que durante la Segunda Guerra Mundial habían sido obligados a trabajar para los alemanes en la Francia ocupada accedieron a las compensaciones económicas establecidas por la RFA para los represaliados del III Reich por su raza, religión o ideología. Ellos fueron un caso único de trabajadores forzados reconocidos como víctimas del nazismo en

\footnotetext{
${ }^{64}$ Nota del ministro del Interior de Renania del Norte Westfalia al Jefe de la Cancillería del Land sobre las indemnizaciones a los Rotspanier, 28.8.1969, LAV NW 1163, Nr. 123.

${ }^{65}$ Ministro de Interior de Renania del Norte Westfalia al Ministerio Federal de Finanzas, 26.3.1980, LAV NW 1163, Nr. 124.
} 
aplicación de la BEG, que excluía a los millones de personas explotadas por la Alemania de Hitler. El largo y complejo proceso judicial que hizo posible a los Rotspanier ser reconocidos como perseguidos politicos del nazismo, y que aquí hemos apenas bosquejado, obligará a reescribir el relato canónico sobre la historia de las indemnizaciones a los trabajadores forzados durante la Segunda Guerra Mundial. Según este, fue solo a finales de los años noventa, como consecuencia de una nueva conciencia social, impulsada en parte por películas como La Lista de Schindler, así como por una cascada de demandas particulares a empresas alemanas y de cambios legislativos impuestos por sentencias judiciales, cuando finalmente la RFA reconoció a los trabajadores forzados del III Reich como víctimas del nazismo y disponibilizó fondos para resarcirlos económicamente.

Los trabajadores forzados del Muro Atlántico fueron el más numeroso, pero no el único grupo de españoles exiliados represaliados por el III Reich que ocuparon a los Servicios de Indemnizaciones de la RFA a partir de los años cincuenta. También hubo deportados a campos de concentración, presos en cárceles del Reich o en campos de internamiento de la Francia ocupada, reclutados a la fuerza para trabajar en Alemania, además de familiares de los fallecidos en aquellos centros de represión o de civiles asesinados por la Wehrmacht, que solicitaron una indemnización al amparo de la BEG y que, en muchos casos, tuvieron que acudir, como los españoles de la OT, a los tribunales para ver reconocidos sus derechos. La lucha de no menos de 15.000 exiliados de la Guerra Civil o sus familias para obtener una indemnización alemana como víctimas del nazismo es un tema inexplorado y con gran potencial para la historia social, la historia del Derecho y la historia transnacional durante la guerra fría. Pero además, como hemos visto en el caso de los trabajadores forzados, los procesos judiciales asociados a las indemnizaciones alemanas abren nuevas e interesantes perspectivas al conocimiento de la historia de los más de cien mil exiliados españoles en Francia que se vieron arrastrados por el torbellino de la Segunda Guerra Mundial.

Entre los más de veinte millones de europeos sometidos a trabajados forzados por la Alemania nazi, los ca. 40.000 Rotspanier representan un número ínfimo. Sus peculiares características como exiliados politicos de un país no beligerante pero simpatizante del Eje y considerados por las autoridades de Vichy y Berlín como enemigos ideológicos a los que había que controlar y reprimir, les otorgó sin embargo unos rasgos únicos, según probó la Justicia alemana hace ya medio siglo. Ese amplio 
grupo de antifascistas atrapado entre tres regímenes hostiles constituye un desideratum de la historiografía del trabajo forzado en la Segunda Guerra Mundial. Entre otras cosas, los Rotspanier ayudarán a profundizar en los mecanismos represivos de aquella suerte de estado dentro del estado nazi que fue la OT, y que aun hoy son muy poco conocidos. Además de arrojar luz en sus condiciones de vida, la historiografía deberá determinar el número exacto de trabajadores forzados españoles y localizar los campos en que estuvieron, no solo en Francia y en las Islas del Canal sino en toda la Europa de Hitler; una labor que los jueces dejaron a medias por interesarles apenas los campos en que fueron recluidos los demandantes de indemnización. También la historiografía del exilio republicano se enfrenta al reto inaplazable de incorporar a los trabajadores forzados en el relato global sobre la España expatriada de 1939, y que en lo referente a Francia se ha concentrado en los resistentes y los deportados, estos últimos considerados, ahora sabemos que de forma equivocada, como los únicos perseguidos políticos españoles del régimen nacionalsocialista.

Fallecidos todos los protagonistas de esta historia, queda en manos de las nuevas generaciones decidir el lugar que los republicanos forzados a servir al III Reich deben ocupar en la memoria democrática de su país de origen. De momento, nada parece perturbar el profundo desinterés oficial hacia estos exiliados. En marzo de 2020, un senador socialista preguntó en sede parlamentaria si el gobierno pretende reconocer a los españoles del Muro Atlántico como víctimas del nazismo de la misma forma que hace Alemania ${ }^{66}$. La respuesta evasiva del gobierno ${ }^{67}$, aparte de despertar legítimas dudas sobre las motivaciones y los objetivos de la ley por él mismo impulsada, que establece un día de homenaje a "todas las víctimas del nazismo en España”, viene una vez más a recordarnos cuán sinuosa y compleja es la relación entre la memoria y la historia.

\footnotetext{
66 Pregunta del senador Santiago José Castellà Surribas al gobierno, 6.3.2020. https://www.senado.es/web/expedientdocblobservlet?legis=14\&id=12852

67 Respuesta del gobierno al senador Santiago José Castellà Surribas, 19.5.2020. https://www.senado.es/web/expedientdocblobservlet?legis=14\&id=30257
} 


\section{BIBLIOGRAFÍA}

Allen Michael T. Hitler's Slave Lords. The Business of Forced Labour in Occupied Europe, Gloucestershire: Tempus, 2004.

Arnaud, Patrice. Les STO. Histoire des français requis en Allemagne nazie, 1942-1945, París: CNRS, 2010.

Borggräfe, Henning. Zwangsarbeiterentschädigung: Vom Streit um 'vergessene Opfer' zur Selbstaussöhnung der Deutschen, Göttingen: Wallstein, 2014.

Brenneis, Sara J. Spaniards in Mauthausen. Representations of a Nazi Concentration camp, 1940-2015, Toronto: University of Toronto Press, 2018.

Carr, Gilly y Caroline Sturdy Cools. "Taboo and Sensitive Heritage: Labour camps, burials and the role of activism in the Channel Islands, 1940-1945", International Journal of Heritage Studies, 22-9 (2016): 702-715.

Crespo, Martí. Republicanos en los campos nazis del Canal de la Mancha, Barcelona: UOC, 2015.

Dreyfus-Armand, Geneviève. El exilio de los republicanos españoles en Francia, Barcelona: Crítica, 2000.

Dubernat, Jean-Guy. L'Organisation Todt. Une organisation allemande au coeur de la collaboration, Rennes: Ouest-France, 2014.

Estrade, Paul (dir.). El trabajo forzado de los españoles en la Francia de Vichy. Los GTE en Corrèze (1940-1944), Madrid: UNED, 2017.

Gaida, Peter. L'Organisation Todt en France, s.1.: Lulu, 2016.

--. "Les étrangers en surnombre". Les Groupements de travailleurs étrangers (GTE) sous le régimen de Vichy, s.1.: Lulu, 2016.

García, Gabrielle. Plaza de los Republicanos españoles. Testimonio de exiliados en Bretaña, Zaragoza: Comuniter, 2015.

García Pérez, Rafael. "El envío de trabajadores españoles a Alemania durante la segunda guerra mundial", Hispania, XLVIII/170, (1988): 1031-1065.

Gnirs, Otto. "Die Entschädigungsbehörden", en Bundesminister der Finanzen (ed.), Wiedergutmachung nationalsozialistischen Unrechts durch die Bundesrepublik Deutschland, Band VI, München: Beck, 1987.

Heine, Harmut. "El envío de trabajadores españoles a la Alemania nazi, 1941-1945", Migraciones y Exilios, 7 (2006): 9-26.

Herbert, Ulrich. Fremdarbeiter. Politik und Praxis des „Ausländer-Einsatzes“ in der Kriegswirtschaft des Dritten Reiches, Bonn: Dietz, 1999.

Hockers, Hans Günter. "Anwälte der Verfolgten. Die United Restitution Organisation", en Ludolf Herbst, Constantin Goschler (eds.), Wiedergutmachung in der Bundesrepublik Deutschland, München: Oldenbourg, 1989.

--. "Wiedergutmachung in Deutschland. Eine historische Bilanz 1945-2000", Vierteljahrshefte für Zeitgeschichte, 49 (2001), Heft 2: 167-214.

Hockers, Hans Günter, Claudia Moisel y Tobias Winstel (eds.). Grenzen der Wiedergutmachung. Die Entschädigung fur NS-Verfolgte in West- und Osteuropa 1945-2000, Göttingen: Wallstein, 2006.

Homze, Edward L. Foreign Labor in Nazi Germany, Princeton: Princeton University Press, 1967. 
Janué i Miret, Maurició. “'Woe Betide Us If They Win!': National Socialist Treatment of the Spanish 'Volunteer' Workers", Contemporary European History, 23/3 (2014): 329-357.

Kaufmann, H. W. et al. The Atlantic Wall: History and Guide, Barnsley: Pen \& Sword, 2012.

Lehmann, Walter. Die Bundesrepublik und Franco-Spanien in den 50er Jahren, München: Oldenbourg, 2006.

Lemmes, Fabian. Arbeiten für das Reich. Die Organisation Todt in Frankreich und Italien, Firenze: Ph. D. European University Institute, 2009.

Marcos, Violette y Juanito Marcos. José Ester Borras... Une vie de combats (19131980), Les cahiers du Coquelicot, $\mathrm{n}^{\circ} 9$.

Miquel, Marc von. "Juristen: Richter in eigener Sache", en Norbert Frei (ed.), Karrieren im Zwielicht. Hitlers Eliten nach 1945, Frankfurt am Main: Campus, 2001.

Pike, David W. "Les îles anglo-normandes sous l'occupation allemande et la singularité des Républicains espagnols en captivité", en Guerres mondiales et conflits contemporains, 4 (2015): 59-78, y 1 (2016): 119-138.

--. Spaniards in the Holocaust: Mauthausen, the Horror on the Danube, London: Routledge, 2000.

Pross, Christian. Der Kleinkrieg gegen die Opfer, Frankfurt am Main: Philo, 1988.

Rodríguez Jiménez, José Luis. Los esclavos españoles de Hitler. La historia de los miles de españoles enviados a trabajar a la Alemania nazi, Barcelona: Planeta, 2002.

Raßlof, Steffen. Fritz Sauckel. Hitlers ,, Muster-Gauleiter“ und ,Sklavenhalter“, Erfurt: Landeszentrale für politische Bildung Thüringen, 2008.

Rechtsprechung zum Wiedergutmachungsrecht, 18 (1967).

Ruiz García, Carlos. Cartas a un amigo. 1939-1944: un republicano español de Barcelona a Burdeos, s.l.: Pleine Plage, 2011.

Schüler-Springorum, Stefanie. Krieg und Fliegen. Die Legion Condor im Spanischen Bürgerkrieg, Padeborn: Ferdinand Schöningh, 2010.

Seidler, Franz. Die Organisation Todt. Bauen für Staat und Wehrmacht, Koblenz: Bernard\&Graefe, 1987.

Soo, Scott. "Ambiguities at Work: Spanish Republican Exiles and the Organisation Todt in Occupied Bordeaux", Modern and Contemporary France, 15 (2007): 457477.

Speer, Albert. Spandauer Tagebücher, Berlin: Propyläen, 1994.

Spoerer, Mark. Zwangsarbeit unter dem Hakenkreuz. Ausländische Zivilarbeiter, Kriegsgefangene und Häftlinge im Deutschen Reich und im besetzten Europa 1939-1945, Stuttgart/Munich: DVA, 2001.

Supreme Headquarters Allied Expeditionary Force, Counter-Intelligence Sub-Division, Handbook of the Organisation Todt, London: MIRS, 1945.

Tooze, Adam. Ökonomie der Zerstörung. Die Geschichte der Wirtschaft im Nationalsozialismus, Bonn: bpb, 2007.

Tuban, Grégory. Camps d'Étrangers. Le contrôle des réfugiés venus d'Espagne (19391944), Paris: Nouveau Monde, 2018.

Zwangsarbeit. Die Deutschen, die Zwangsarbeiter und der Krieg, Stiftung Gedenkstätten Buchenwald und Mittelbau-Dora. Weimar, 2010. 


\begin{abstract}
ANEXO
Lista de campos de la Organizacion Todt en la costa de Francia y en las Islas del Canal asignados a la construcción del Muro Atlántico en los que el Servicio de Indemnizaciones a víctimas del nazismo de la RFA dio por probado que los republicanos españoles allí enviados contra su voluntad habían sido privados de libertad. Los exiliados españoles internados en alguno de estos campos en el periodo indicado son, por tanto, considerados por la RFA como víctimas del nazismo.
\end{abstract}

\title{
PAS DE CALAIS
}

Calais

22.6.1941 - 31.8.1944

Boulogne

22.6.1941 - 31.8.1944

Dannes

22.6.1941 - 31.8.1944

Camiers

22.6.1941-31.8.1944

NORMANDIA

Brix, Cherburgo

22.6.1941 - 10.8.1944

Couville

22.6.1941 - 10.8.1944

ISLAS DEL CANAL

Alderney o Aurigny

$01.1 .1941-08.5 .1945$

Guernsey

$01.1 .1941-08.5 .1945$

Jersey

$01.1 .1941-08.5 .1945$

\section{BRETAÑA}

Caserne Concorde - Saint Servan, Saint Malo

22.6.1941- 17.8.1944

Clos Cadot, Saint Malo

$22.6 .1941-17.8 .1944$

Saint Malo

$22.6 .1941-17.8 .1944$

Fort Montbarey, Brest

$22.6 .1941-10.9 .1944$

Caserne Concorde, Saint Pierre Quilbignon, Brest

$22.6 .1941-10.9 .1944$

Sainte-Anne de Portzic, Brest

22.6.1941 - 10.9.1944

Brest

$22.6 .1941-10.9 .1944$

Hennebont, Lorient

$22.6 .1941-10.8 .1944$

Le Croisic, Saint-Nazaire

$22.6 .1941-10.8 .1944$

Montoir de Bretagne, Saint-Nazaire

22.6.1941-10.8.1944

\section{CHARENTE}

La Pallice, La Rochelle

22.6.1941 - 30.9.1944

Montendre

22.6.1941 - 15.12.1943

\section{BURDEOS}

Caserne Coloniale

22.6.1941 - 15.8.1944

Caserne Niel

22.6.1941 - 31.7.1943

Fort du Hâ

22.6.1941 - 15.8.1944

Saint Médard en Jalles

22.6.1941 - 15.8.1944 
ANTONio Muñoz SÁNCHEZ
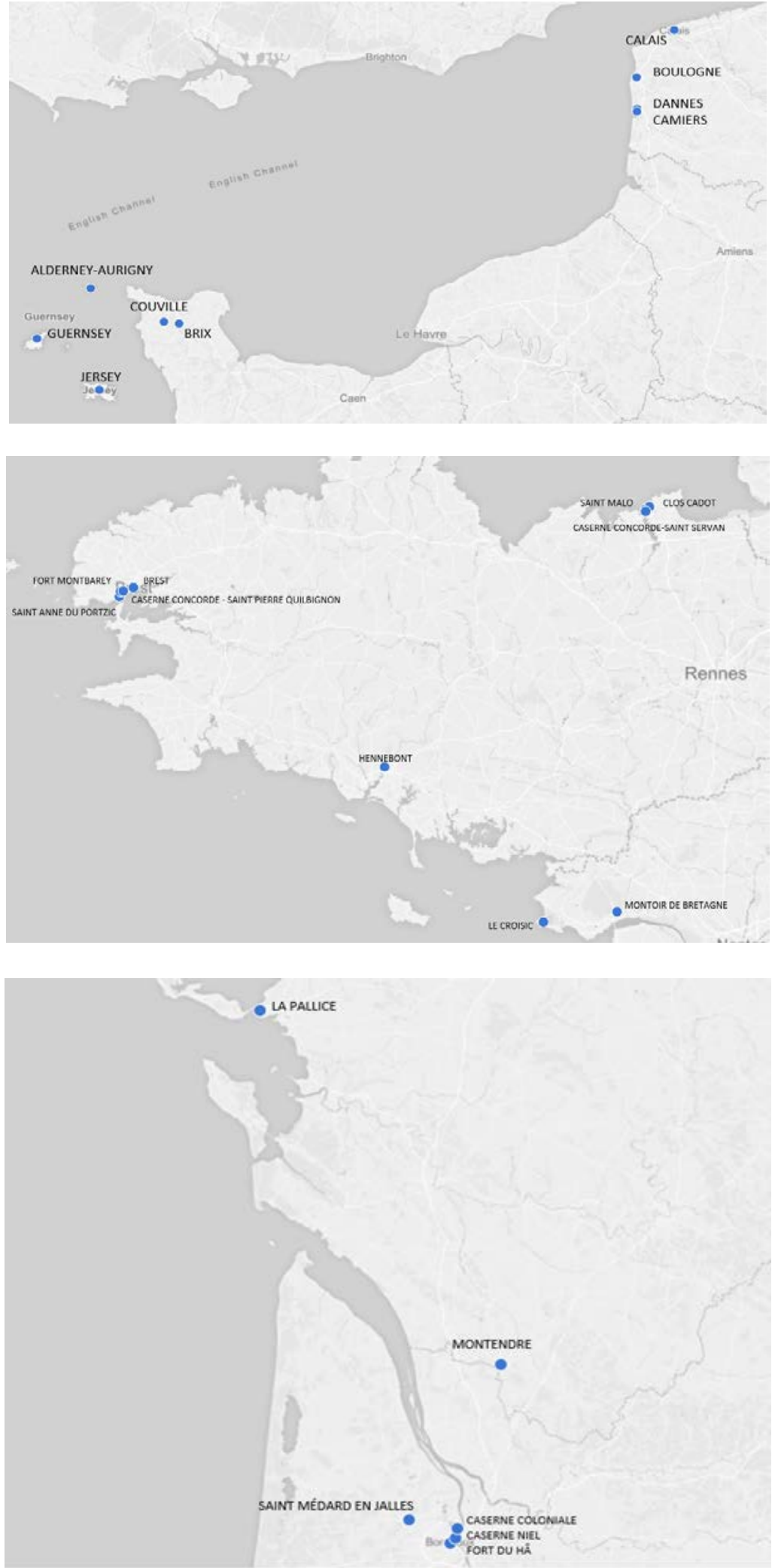

Fuente: Lista de campos indemnizables en Francia y las Islas del Canal elaborada por el Servicio de Indemnizaciones de Colonia, 12.6.1972, LAV R 2614, Nr. 68. 